\title{
Hepatitis C Virus (HCV) Specific Sequences Are Demonstrable in the DNA Fraction of Peripheral Blood Mononuclear Cells from Healthy, Anti-HCV Antibody-Negative Individuals and Cell Lines of Human Origin
}

\author{
Reinhard H. Dennin and Zhi Chen
}

Institut für Medizinische Mikrobiologie und Hygiene, Medizinische Universität zu Lübeck, Lübeck, Germany

Summary: No convincing support has been provided so far for the existence of extrahepatic hepatitis $\mathrm{C}$ virus particles that should correspond to the sometimes extremely high concentration of 'HCV-RNA' in serum or plasma. If a naturally occuring HCV-specific DNA were to be found, a concept for at least some phenomena in terms of the pathophysiology of HCV should become conceivable. DNA was extracted from peripheral blood mononuclear cells of eleven healthy, anti-HCV-negative individuals, including five long term blood donors, and cells from different cell lines. DNA was subjected to nested polymerase chain reaction omitting a reverse transcriptase step with primers of the $5{ }^{\prime} \mathrm{NC}$ as well as part of the core region of HCV. Direct polymerase chain reaction, i.e. without a reverse transcriptase step, revealed HCV-specific sequences in the DNA fraction of peripheral blood mononuclear cells of different origin: healthy anti-HCV negative individuals, furthermore in HeLa and MT2 cells. The fragments found were of expected length as well as of shorter and of longer than expected length with respect to the sequence of the HCV genome framed by the primers applied. The results derived from additional hybridization, restriction endonuclase analysis, and sequencing demonstrated HCV-specific sequences in the expected fragments with both a high degree of homology and deletions, respectively, substitutions, as compared to a prototype strain. However, the longer than expected fragments also contained sequences not specific for $\mathrm{HCV}$.

\section{Introduction}

The detection of HCV specific DNA sequences in tissue samples of liver from anti-HCV positive German intravenous drug users and Chinese patients with primary hepato-cellular carcinoma (1) was accomplished utilizing primers for direct polymerase chain reaction ( $\mathrm{dPCR}$, i. e. without a reverse transcriptase step) spanning parts of the 5'NC- and C-regions. One of the most probable reasons for the relatively low rate of detection was supposed to be the selection of primers used in previous investigations. We therefore decided to select other primer sets that span shorter fragments, especially from a 5 NC and $\mathrm{C}$ section of HCV not loaded with stem loop structures. This was done with regard to mounting hints that the 5 'NC region is exceptionally important for the development and maintenance of the chronic stage of $\mathrm{HCV}$ infection and possibly the development to hepatocellular carcinoma $(2,3)$. In our previous investigations we have already obtained indications of $\mathrm{HCV}$ specific sequences being present in the DNA of individuals testing anti-HCV negative. Therefore, both peripheral blood mononuclear cells from healthy, anti-HCV negative individuals, one patient with acute hepatitis $\mathrm{C}$, and different cell lines were included in the present study.

\section{Materials and Methods}

Sources for DNA and RNA extraction

Isolation of peripheral blood mononuclear cells

From eleven healthy, anti-HCV negative individuals, and one patient with acute hepatitis $\mathrm{C}, 10 \mathrm{ml}$ venous blood were drawn and immediately adjusted with EDTA-Na to give a final concentration of $5 \mathrm{mmol} / 1$. This EDTA-plasma $(10 \mathrm{ml})$ was mixed with $10 \mathrm{ml}$ phosphate-buffered saline with EDTA-Na, $1 \mathrm{mmol} / \mathrm{l}, \mathrm{pH}$ 7.8. This mixture was layered onto $15 \mathrm{ml}$ Histopaque, density $1.077 \mathrm{~kg} / \mathrm{l}$ (Sigma, München, Germany) and centrifuged for $20 \mathrm{~min}$ at 1080 $\min ^{-1}(200 \mathrm{~g})$ at $20^{\circ} \mathrm{C}$. Three ml of the upper part of the supernatant was recovered and stored for further assays and the cell-containing layer above the histopaque collected. The cells were sedimented at $1080 \mathrm{~min}^{-1}$ and resuspended in phosphate-buffered saline (plus $10 \mathrm{mmol} / \mathrm{l}$ EDTA-Na). This washing step was repeated two times. Finally, the cell harvest was resuspended in $1 \mathrm{ml}$ phosphate-buffered saline (plus $10 \mathrm{mmol} / 1$ EDTA-Na) and used for extraction of DNA (see below).

HeLa (cervical carcinoma), H9 and MT2 (T-cell lines) cells Cells were taken from

(i) frozen $\left(-70^{\circ} \mathrm{C}\right)$ samples of cell cultures that had been stored without any handling since 1988 , i. e. long before any experiments concerning $\mathrm{HCV}$ had been conducted in our laboratories.

(ii) Cells were also taken from continuous cell culture passages. Cell culture passages were performed according to standard procedures in MEM(E) (Biochrom, Berlin, Germany) for HeLa cells, and RPMI (Biochrom) for H9 and MT2 cells. The media were both supplemented with newborn calf serum (Biochrom). 
(iii) Additionally, we assayed two commercial genomic HeLa DNA preparations (ITC/Clontech, Heidelberg, Germany): One sample was ordered and investigated 5/1994, and another one in 7/1995.

\section{Enzyme immunoassay of HCV antibodies}

The anti-HCV EIA (Abbott, Wiesbaden, Germany), RIBA 2 resp. 3 (Ortho, Neckargmünd, Germany) and Matrix (Abbott) assays in sera were performed according to the manufacturer's instruction.

\section{Extraction of deoxyribonucleic acid}

The procedures were the same as outlined in a previous paper (1). In brief: A cell pellet from the final harvest (see above) was digested with proteinase $\mathrm{K}(0.1 \mathrm{~g} / \mathrm{l}$, Tris EDTA buffer $\mathrm{pH}$ 8.0: Tris 10 $\mathrm{mmol} / \mathrm{l}$, EDTA $1 \mathrm{mmol} / \mathrm{l}$ ), extracted twice with phenol/chloroform/ isopropanol $(25+24+1, \mathrm{pH} 7.9)$ and twice with chloroform/isopropanol $(24+1)$. After precipitation with ethanol, the pellet was washed twice with ethanol (volume fraction 0.70 ) and dissolved in $100 \mu \mathrm{l}$ buffer containing Tris/ $\mathrm{HCl} 10 \mathrm{mmol} / 1$, EDTA $1 \mathrm{mmol} / \mathrm{l}$, pH 8.0.

\section{Polymerase chain reaction (PCR)}

Oligonucleotides: HCV specific primers were synthesized with the Pharmacia 'Genas sembler plus' and by MWG (Ebersberg, Germany), respectively: They were chosen from different conserved regions of the $\mathrm{HCV}$ genome according to published data (see fig. 1). 5'NC-region: set $1 \mathrm{a}$ and set $1 \mathrm{~b} ; 5^{\prime} \mathrm{NC}-\mathrm{C}$ region $=$ set $2 \mathrm{a}$ and set $2 \mathrm{~b}$. For some applications the primers of set $1 \mathrm{~b}$ and $2 \mathrm{~b}$ (inner primers) and probes were labelled at their 5'-end with biotin (BIODITE $^{\mathrm{TM}}$, Biotin Amidite, Pharmacia, Freiburg). The sequences of all primers and probes used in this study were checked for homology with the sequence of the HCV strain published by Choo et al. (5) (source: EMBL, Heidelberg) with the Genmon 5 program (GBF, Braunschweig, Germany). Both reaction mixture and PCR methodology were essentially the same as outlined previously (1), with one exception. The denaturing step was only for 1 min instead of $1.5 \mathrm{~min}$ at $94^{\circ} \mathrm{C}$; and only 30 cycles were applied instead of 35 cycles. Two rounds of PCR were done because of using the visible fragments after gel electrophoresis for cloning and sequencing. Extraction of the fragments in question from the gels for cloning and sequencing was done according to manufacturer's protocol (Agarose gel extraction kit, Boehringer, Mannheim).

Safety procedures to avoid contaminations were follwed according to the state of the art, especially the use of separate rooms for each step of the PCR procedure. When setting up a PCR assay the arrangement for the reaction tubes was as follows:

1. negative control, i.e., a complete reaction mix, but without a DNA matrix

2. complete reaction mix with a preparation that could contain DNA,

3. negative control, etc.; the arrangements shown in figures 2 and 3 were made by loading the gel slots with selected products after direct PCR for comprehensive demonstration.

\section{Hybridization and detection of labelled fragments}

The procedures were the same as outlined previously (1). The development of biotin labelled probes or fragments (via 5'-biotin labelled primers) after transfer to a positively charged Nylon membrane was done with anti-biotin labelled peroxidase (Boehringer, Mannheim) according to the manufacturer's instructions.

Alternatively we used digoxigenin labelled probes (PTNC-P) (DIG Oligonucleotide 3'-End Labelling Kit and DIG Nucleic Acid Detection Kit, Boehringer, Mannheim) beside those labelled with biotin.

Sequence analysis

Fragments after PCR and gel electrophoresis were cloned with the TA Cloning kit, pCR2.1 Vector (INVITROGEN, Leek, Netherlands). For sequencing, the Dig Taq DNA sequencing kit (Boeh- ringer, Mannheim) was used or sequencing was done by MWG (Ebersberg, Germany). Searches for sequence homologies were conducted with the DNA databank at the EMBL (Heidelberg, Germany).

\section{Enzymatic ${ }^{1}$ ) analysis}

The restriction endonucleases AvaII, HpaII and SmaI (Pharmacia, Freiburg) were used according to the manufacturer's instructions. DNase and RNase challenge: DNase, 20 units per $50 \mu \mathrm{l}(400 \mathrm{kU} / \mathrm{l})$ final concentration (RNase free, Boehringer) and RNase, $20 \mathrm{mg} / 1$ final concentration (DNase free, Boehringer) were applied according to the manufacturer's instructions.

\section{Results}

In the present study we have been looking for naturally occuring HCV DNA with primers of the 5 'NC- and Cregion for the nested direct PCR protocol (i.e. PCR without a preceding reverse transcriptase step) in different sources for DNA. Peripheral blood mononuclear cells from healthy, anti-HCV negative individuals, some of them registered blood donors, cells from continuous cultures: HeLa, H9 and MT2 (the status with regard to an 'HCV infection' of those source individuals is not known), and one case of an acute hepatitis C. Products after direct PCR were assayed by hybridization, restriction endonuclease fragment length analysis, and mostly sequencing. Of the peripheral blood mononuclear cells samples from healthy individuals (four females, seven males) 10/11 (set 1 primers) and 7/8 (set 2 primers) (details for location of primers see fig. 1) assayed samples had fragments containing HCV specific sequences. In the present paper we have focused on the fragments generated by direct PCR with set $1 \mathrm{a}, \mathrm{b}$ primers. In the positive cases the nested direct PCR yielded fragments of the expected length in $9 / 11$, in $1 / 11$ one shorter than expected and in $5 / 11$ additional longer fragments were obtained (selected cases are shown in figs $2 a-c$ ). From certain anti-HCV negative individuals blood was drawn a second time three weeks later and the DNA extracted from peripheral blood mononuclear cells. The results, i. e. the individual 'band pattern' (= the relative position of fragments of different length in the gel) were identical for the given individual thus excluding a contamination. However, peripheral blood mononuclear cells samples prepared later showed fragments of longer than expected length at different positions (see below for details). The specificity was assayed by hybridization (fig. $2 b$ ) with a probe (PTNC-P) whose sequence is located between the inner primers of set 1 . The corresponding stronger band

\section{1) Enzymes}

DNaseI (RNase-free): Deoxyribonuclease I (EC 3.1.21.1)

Proteinase K: Endopeptidase K (EC 3.4.21.64)

Restriction enzymes: Type II site-specific deoxyribonuclease (EC 3.1.21.4)

RNase I (DNase-free): Pancreatic ribonuclease (EC 3.1.27.5)

Taq polymerase: DNA-directed DNA polymerase (from Thermus aquaticus) (EC 2.7.7.7) 


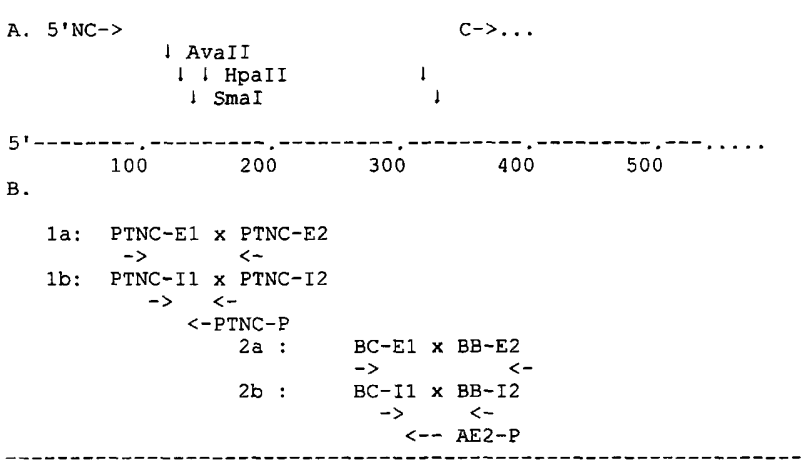

Fig. 1 Hepatitis $\mathrm{C}$ virus: $5^{\prime} \mathrm{NC}$ and $\mathrm{C}$ region of the genome with location of primers, probes, and cutting sites of restriction enzymes used (AvaII, HpaII, and SmaI).

A: Relative arrangement of genomic regions: $\mathrm{NC}=$ non-coding, $\mathrm{C}=$ core (nucleocapsid).

B: Primers used, in brackets the nucleotide number is given according to the prototype HCV strain described by Choo et al. (5) (EMBL, Heidelberg). References are given in parenthesis.

5 NC-region:

set 1a: PTNC-E1 [89-108], PTNC-E2 [152-170],

set 1b: PTNC-I1 [99-118], PTNC-I2 [139-158],

PTNC-P = digoxigenin labelled probe $[122-141](24)$;

5 NC-C region:

set 2a: BC-E1 [268-297], BB-E2 [387-416];

set 2b: BC-I1 [284-305], BB-I2 [381-403]; AE2-P = digoxigenin labelled probe [299-328] (25);

-E.: external, -I.: internal, -.1: sense, -.2: antisense;

$<>$ arrows indicate broadly the start position of primers,

$\downarrow$ arrows indicate broadly the cutting sites of the restriction enzymes used here.

of the gel (e.g., arrow: ' $\square$ ' lane $6, \approx 115$ base pairs, fig. 2a) containing longer fragments than expected did not yield a strong signal after hybridization. The restriction endonuclease fragment length analysis also gave results not in accordance with the assumption of regular unique arrangements of the sequence according to the ' $\mathrm{HCV}$ RNA genome'. The fragments of expected length were cut (arrows: ' $>$ ', figs $2 a$ and $b$ ) resulting in smaller fragments, whereas the longer fragments remained unchanged (fig. 2a). After restriction endonuclease fragment length analysis with HpaII and SmaI the products of the digest with the expected fragment (lane 6, fig. 2a) could no longer be hybridized with the PTNC-P probe for set 1, whereas the digest by AvaII showed positive signals with the same probe (fig. 2b). This is to be expected because HpaII and SmaI cut within the sequence matching the probe, however, AvaII cuts outside thus leaving the sequence matching that of the probe. Furthermore, serum samples from three healthy individuals enrolled in this study were also assayed for HCVRNA by reverse transcriptase PCR with set 1 primers. After gel electrophoresis fragments of the expected length were present, and for one case (individual 2: lanes 6 to 9 , fig. 2a) an additional fragment of longer than expected length was also present (results not shown here). The data show the fragment at the expected position to contain the respective sequence ("e", fig. 4) of

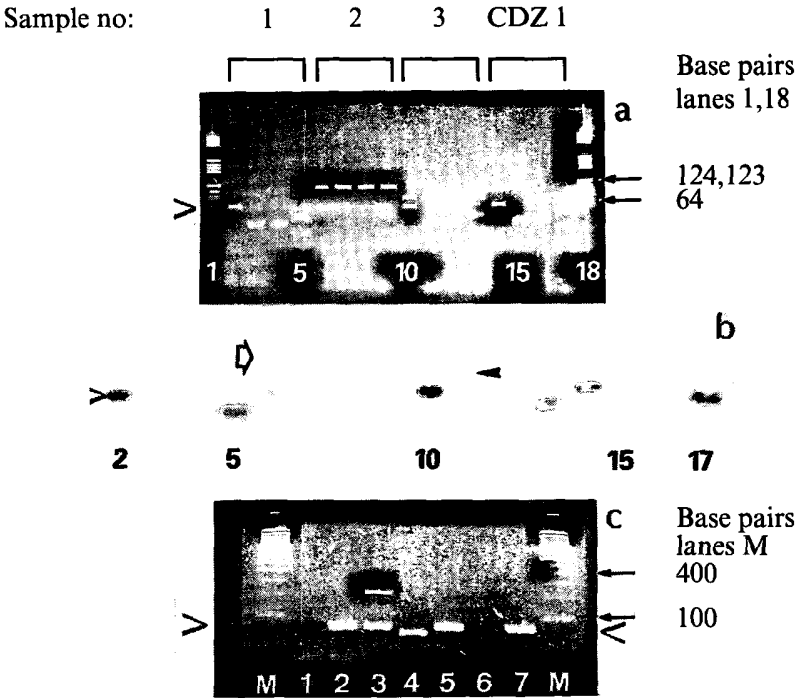

Fig. 2 a) Results after direct PCR (primer set $1 b$, see fig. 1) and restriction endonuclease fragment length analysis (RFLA) of DNA prepared from peripheral blood mononuclear cells of healthy antiHCV negative individuals. Samples 1 (lanes 2-5), 2 (lanes 6-9), 3 (lanes $10-13$ ), and $\mathrm{CDZ1}$ (= cloned fragment of the $5^{\prime} \mathrm{NC}$ region covering nucleotides 66 to 321) positive control (lanes 14-17). Lanes 3, 7, 11, and 15 after digest with HpaII; lanes 4, 8, 12, and 16 with $S m a I$; lanes 5, 9, 13, and 17 with AvaII respectively. The bands at the expected position (arrow: '>'; no 2 = sequence " $\mathrm{e}$ ", fig. 4) can be digested by all enzymes, the longer bands of 2 (arrow: ' $D$ ') and 3 cannot. Lanes 1 and 18 , molecular mass marker (Boehringer type V). The samples shown in the lanes were taken from different PCR assays and arranged here for this picture. The arrangement of loading the slots in the original gel is always: blank/sample/blank/sample/blank etc.; gel electrophoresis in $2 \%$ agarose.

b) Hybridization with digoxigenin labelled oligo-PTNC probe (= PTNC-P, see fig. 1) after direct PCR and restriction enzyme analysis (same arrangement as shown in part a); lanes 2, 6, 10 and 14 , all bands of the untreated samples ( $=$ without restriction enzyme digest) at the expected position show positive signals; lanes 6 to 9 , the longer band of $2(\approx 115$ base pairs, arrow: ' $D$ ') presents weakly; lanes 10 to 13 , the longer band of $3(\approx 85$ base pairs, arrow: ' -') presents very weakly, only visible on the original membrane (at higher temperature $57^{\circ} \mathrm{C}$ instead of $54^{\circ} \mathrm{C}$ these bands are no longer visible).

c) Results after direct PCR (primer set 1b) of DNA from peripheral blood mononuclear cells of additional healthy anti-HCV negative individuals in lanes 2-5. Lane 1, blank (negative) control: PCR master mix without any target DNA; lane 2, same individual (sample 1) as shown in lanes $2-5$, fig. 2 a but here peripheral blood mononuclear cells prepared from a sample taken 40 months later; lane 3 , is the same individual (sample 2) as shown in part 2a, but here peripheral blood mononuclear cells prepared 40 months later; lane 4 , shows a shorter than expected fragment; lane 5 , healthy individual; lane 6, blank control: PCR master mix with pUC18 plasmid DNA, $100 \mathrm{ng}$; lane 7, CDZ1 positive control (see part 2a); lanes $M$, molecular mass marker, 100 base pair ladder; arrows ' $>$ ' and ' $<$ ' point at the fragments of expected length $=60$ base pairs; sequences see figure 4 ; arrows ' $\leftarrow$ ' pointing at the 100 and 400 base pair fragments of the molecular mass marker; gel electrophoresis in $4 \%$ agarose.

the HCV reference strain ${ }^{2}$ ). From this individual (fig. 2) further DNA preparations from peripheral blood mono-

${ }^{2}$ ) In this manuscript only the data after sequencing of the fragments of expected length are considered, the respective data of the longer than expected fragments are not discussed (manuscript in preparation). 
nuclear cells 16 months $(8 / 1995)$ and 40 months later were analyzed with the same primers by direct PCR. The results after gel electrophoresis and hybridization show a different pattern: besides the fragment of expected length, two fragments of 'longer than expected length' were present in 8/1995 (results not shown here) and only one additional longer fragment in 8/1997 (lane 3 , fig. 2c). From another healthy individual a fragment of shorter than expected length was detected. The sequence shown in lane 4 , figure $2 \mathrm{c}$ presents a deletion of 14 nucleotides and two single point substitutions, see sequence "c", figure 4 . The sequencings were done on both strands of the cloned fragments. The sequences are identical for both strands in "c", "d", "f", and "g". For "e", the sequence for only one strand was available. For sequence " $b$ " one strand is identical to the respective region of the reference strain, the other strand shows one $\mathrm{C}$-nucleotide less in the ' $\mathrm{CCCCCCC}$ '-section. We think this deletion to be due to the sequencing procedure.

We further extended the search for HCV specific sequences in the DNA of quite different cell lines used in our laboratory for virus propagation HeLa, H9 and MT2. These cell lines were passaged in a special laboratory for cell cultures that had never been in contact with any step of PCR. After direct PCR with the set 1 as well as the set 2 primers (see fig. 1) followed by gel electrophoresis we were able to obtain positive signals from HeLa, H9 and MT2 cells at the expected positions (arrows: ' $D$ ', figs. $3 \mathrm{a}, \mathrm{b}$ ), and partly additional single longer or multiple longer than expected fragments (arrows: ' $\rightarrow$ ', figs. 3a, b, all for primer set 1). The 'band pattern' was different among the cell lines used here but was the

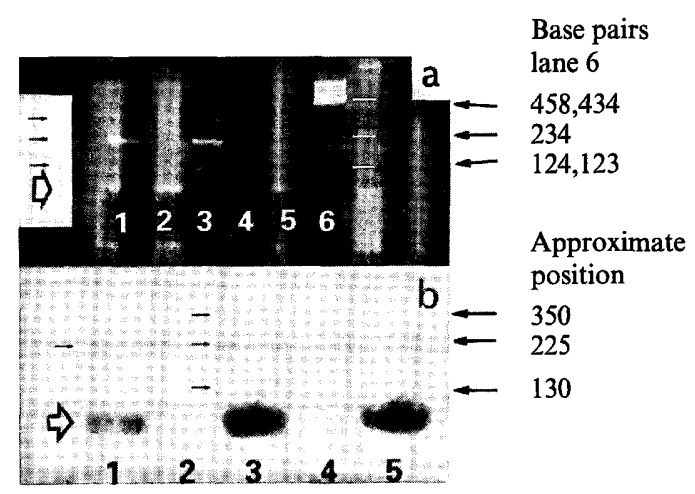

Fig. 3 a) Results after direct PCR with PTNC primers (set lb) with DNA from different cell culture lines. Lane 1, HeLa; lane 2, H9; lane 3, MT2; lane 4, negative control = PCR buffer including primers and $T a q$ polymerase, without target DNA; lane 5, positive control = CDZ1; lane 6, molecular mass marker (Boehringer type V) with arrows ' $\leftarrow$ ' pointing at selected positions.

b) Results after blotting and hybridization with digoxigenin labelled oligo-PTNC probe (PTNC-P, see fig. 1) of the gel shown in part a (= same arrangement). The longer (containing fragments of higher molecular mass than expected) bands at $\approx 225$ base pairs (lane 1 ) and at $\approx 130, \approx 225$ and $\approx 350$ base pairs (MT2) (small arrows: ' $\rightarrow$ ') show positive signals beside the expected band (arrow: ' $(\downarrow$ '). $\mathrm{H} 9$ does not show any signal after hybridization. same for a given sample upon repetition, when using material from a new extraction.

Furthermore we employed genomic HeLa DNA from inhouse cell cultures extracted and stored at $-70^{\circ} \mathrm{C}$ since 1988 as well as two different lots of genomic HeLa DNA purchased from ITC-Clontech: the 'band pattern' after direct PCR in the gel was similar although not identical concerning the position in the gel to those used from our laboratory (s. Material and Methods). The hybridization with the PTNC-P probe for set 1 primers gave positive signals only for the HeLa and MT2 cells (fig. 3b). Whether the lacking signal after hybridization in lane 2 , figure $3 \mathrm{~b}$, for $\mathrm{H} 9$ cells is due to the absence of a real fragment or a fragment either with insufficient or lacking homologous sequence for the PTNC-P probe to anneal remains to be clarified by further cloning and sequencing investigations. However, as no signal after hybridization was found for H9-DNA after direct PCR upon all repetitions performed, exclusion of laboratory contamination is warranted. According to the DNA molecular mass marker the primers are positioned just in front of the bands with the expected fragment length. They do not hybridize with the PTNC-P probe (lane $4=$ negative control, fig. 3b). Although the bands containing longer than expected fragments within the gel (arrows: $' \rightarrow$ ' $\approx 130$ base pairs, $\approx 225$ base pairs, $\approx 350$ base pairs, fig. 3a) appear stronger than the expected fragments, their signal after hybridization presents weaker or even negative (fig. $3 b$ ).

Further experiments were performed to assay for the possibility of unspecific priming by e.g. internal fragments of the same DNA that might be present in these preparations of high molecular weight DNA from human cells.

1. By conducting the direct PCR (strictly according to the protocol used) without primers, no bands could be detected either with otherwise positive samples or with DNA from peripheral blood mononuclear cells, HeLa, H9 and MT2 cells.

2. PCRs were conducted during the 'nested' round with PTNC-I1 and -I2 primers (set 1b) whose 5'-ends had been labelled with biotin (see Material and Methods). After development with anti-biotin labelled peroxidase the same pattern could be demonstrated with regard to the position of bands (results not shown).

3. The hot start protocol for PCR was applied. However, the band pattern, i. e., 'fragments of expected as well as of longer than expected length' remained unchanged.

4. The temperature of the primer annealing step of the PCR was adjusted up to $60^{\circ} \mathrm{C}$ - but again the band pattern remained the same.

5. The fragments obtained after direct PCR proved specific for a DNA target: The matrix for direct PCR turned out to be sensitive for DNase treatment but not for RNase treatment of the cell extracts. 


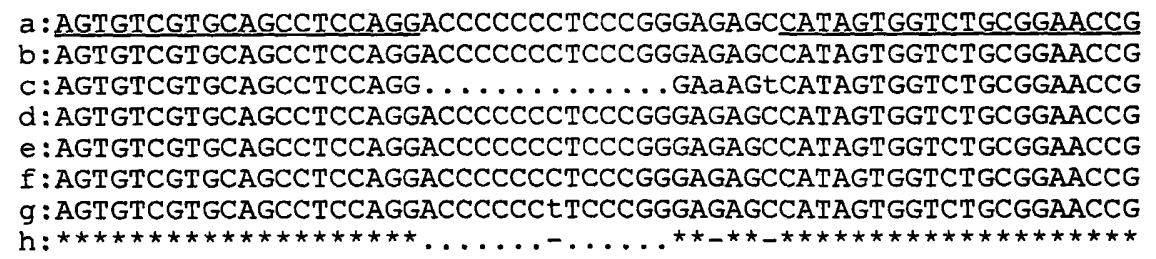

Fig. 4 The alignment of sequences amplified with the primer set $1 a, b$, framing the 'expected' fragment of 60 base pairs; $a$ : The sequence of the HCV strain used as a reference (5), the sequences of the sense and antisense primers are underlined; $b$ : healthy individual, lane 2, figure 2c; c: healthy individual, lane 4, figure 2c; d: healthy individual, lane 5, figure 2c; e: healthy individual (4/1994),

6. The individual 'band patterns' were reproducibly obtained upon repeating the direct PCR assays with the individual extracts of DNA up to six times; when challenged by hybridization of RFLA the results were identical.

7. By conducting the direct PCR including all components, however, only pUC 18 plasmid DNA as a target was applied; no signal after gel electrophoresis was obtained.

\section{Discussion}

Although early investigators failed to detect a naturally occuring HCV-DNA (4) others have found HCV specific DNA sections in the DNA fraction of anti-HCV positive patients (1).

An intriguing situation was obtained after direct PCR with DNA from peripheral blood mononuclear cells from healthy anti-HCV negative individuals: When different primers are applied, fragments of the expected length as well as in some cases fragments of higher relative molecular mass than expected, and in one case a shorter than expected fragment were obtained from these new samples. Furthermore, in HeLa and MT2 cell lines $\mathrm{HCV}$ specific sequences could be detected, fragments of the expected length as well as longer ones.

The contrary results following hybridization (i.e., gel positive, hybridization negative) and restriction endonuclease fragment length analysis (i. e., gel positive, restriction endonuclease fragment length analysis negative) (see fig. $2 a, b)$ become explainable by sequencing data. The sequences bordered by the primers contained in the longer fragments of selected cases show sections of up to 9 or 10 nucleotides matching the respective $\mathrm{HCV}$ sequences of that region (sequences not shown here). This is just adequate to give a weak signal due to partial hybridization at normal stringency conditions when compared to full matching sites in the fragments of expected length which yield strong signals upon hybridization. Ubiquitin specific sequences as shown for a pestivirus, bovine viral diarrhea virus (6) could be excluded in these sequences by conducting a direct PCR with ubiquitin specific primers. A similar situation has to be considered for restriction endonuclease fragment length analysis: for example, the sequences available show the longer fragment in lanes 6 to short fragment of expected size of lane 6, arrow '>', figure 2a; f: same healthy individual as in " $\mathrm{e}$ ", but this sample taken $8 / 1997$, lane 3, figure 2c; g: patient suffering from acute hepatitis $\mathrm{C}$ (the result after gel electrophoresis is not shown here); $h$ : In this line, positions marked: '*' are totally conserved, ' - ' are variable while periods "." indicate regions containing deletions.

9 (arrow: $\Rightarrow$, fig. 2a) not to contain sites for the restriction endonucleases applied. Although few samples have been investigated, the rate of positive results with primer sets downstream of the $5^{\prime} \mathrm{NC}$ region is lower with respect to those of the 5 'NC region itself. This could reflect its importance in regulatory activities warranted by highly conserved sequences with only a small degree of variation (2). The fragments of the expected length show a complete homology with the sequence of the prototype HCV strain (5) for $3 / 4$ cases of healthy anti-HCV negative individuals. This degree of homology has to be seen with respect to the DNA matrix used here for the PCR target. This DNA has been generated in vivo by cellular DNA polymerases known to have excellent capability of proofreading compared with RNA polymerases. Therefore, mutations are almost not expected when using such a DNA matrix. However, in $1 / 4$ cases a shorter than expected fragment (see lane 4, fig. 2c) was detected, the sequence of revealed a deletion of 14 nucleotides (no. 118 to 132 of the sequence used for reference (5)) and two substitutions at positions 135 and 138, respectively. A second blood sample of this individual was taken six weeks later and the peripheral blood mononuclear cells prepared: again, only the shorter than expected fragment was detected after direct PCR. The sequence of the expected fragment of the one patient with acute hepatitis $C$ shows a substitute at position nt 126 .

Since no reverse transcriptase has been detected together with 'HCV', it seems unlikely that these HCV specific DNA sequences are integrated ones derived from external RNAs. The alternative, that the fragments detected were generated by foreign reverse transcriptase activities due to coinciding HIV or HBV infection in the healthy individuals, could be excluded. Only one individual showed serological markers of a previous HBV infection. Furthermore, the possibility of artifacts has to be considered, especially for the 'longer than expected fragments'. Unspecific pick-ups during PCR can be due to annealing of primers to target sequences with a low degree of homology. However: we conducted the PCR at higher annealing temperatures: $58^{\circ} \mathrm{C}, 60^{\circ} \mathrm{C}$ and $62{ }^{\circ} \mathrm{C}$. Yet, the resulting pattern of fragments after gel electrophoresis remained the same. After applying the hot start PCR procedure there was also no change in the 
pattern of fragments. Additional fragments of 'longer than expected length' were reproducibly seen at certain positions for only some of the individuals assayed, e.g. subject 2, figure 2 (not in others!), and HeLa and MT2 cells, thus excluding random unspecific priming at sequences unrelated to the corresponding primer sites. The position of the longer than expected fragments amplified from the DNA of those individuals remained identical for some weeks, yet 16 months and 40 months later it had been replaced by others or had disappeared (see data for case 2, fig. 2a, c). From the results of these additional controls and follow up, we infer that the primers used have a high degree of homology with certain sections of the human target DNA allowing them to anneal even at higher temperatures, i. e. stringency. Therefore, the fragments of expected, as well as of longer than expected, length in some individuals can be ascribed to sequence sections contained in the human DNA.

The findings available so far lend support to the assumption that not all parts necessary for the generation of an active process are present in every individual. HCV specific DNA sequences have already been detected in serum and plasma, especially of patients suffering from severe chronic hepatitis $\mathrm{C}$ (probably due to DNA released from destroyed hepatocytes (7)) as well as HCVRNA in serum samples of healthy anti-HCV negative individuals. One individual (sample 2, fig. 2) already showed an additional 'longer fragment' beside the one of expected length in her plasma upon reverse transcriptase PCR assay. This indicates that

i) already in some 'healthy', anti-HCV negative individuals HCV-RNA can be detected with the highly sensitive reverse transcriptase PCR assay, and

ii) 'longer than expected' RNA-fragments (!) can also be present.

With respect to these findings, HCV-RNA occasionally detected in individuals without any signs of liver disease, such as elevated serum transaminases - without anti-HCV antibodies - would represent some kind of naturally (?) occuring transcripts of the human DNA. To some extent, our findings could reflect the situation insinuated by Miyakawa et al. (8) with respect to the HGV - supposed to be a virus, but without harboring a sequence that could code for a core - as to potentially being an 'accidental tourist'. Conceivable within the framework of a hypothesis, completion of dispersed sequences could either be achieved by exogenous 'infection' with transmissible protected structures containing other lacking segments, DNA or RNA in nature and/or internally by a process such as 'DNA rearrangement'. Depending on incoming or sequences already present this could constitute a situation enabling an active process. The mechanism whereby structures can be established with self-supporting and 'infectious' activities re- mains to be determined. The possibility of a 'DNA-rearrangement' is inferred from the changing pattern of fragments of longer than expected length after following up individual 2 (sample 2, lane 6 to 9, fig. 2a, and lane 3 , fig. 2c): At least two other additional fragments of higher molecular mass than expected were present after 16 months (not shown here), and only one additional fragment of longer than expected length 40 months later. This situation could hint at HCV DNA sequence rearrangements during the course of time.

These findings, demonstrating $\mathrm{HCV}$-specific sequences of the $5^{\prime} \mathrm{NC}$ as well as the core-region to be resident in human DNA, do not harmonize with the current concept of $\mathrm{HCV}$ as a conventional positive single-stranded RNA virus. The findings that the HCV shares amino acid sequence similarities with plant viruses points to the complex situation of an 'elusive agent', indicating a possible recombinant source (9). Furthermore, a short, yet important sequence of the long terminal repeat of HIV (10) could be localized in some, yet not all (!) genotypes of HCV. Recent findings $(11,12)$ describing a so far unknown sequence of 98 nucleotides at the $3^{\prime}$ terminus have also created an unusual situation.

Very tentatively, our results could be interpreted to mean that the HCV specific DNA sequences found and analyzed here represent naturally occuring constituents of the human DNA. Whether they represent essential prerequisites or only contribute to the broad spectrum of situations caused by or associated with HCV remains to be determined. Findings of partial HCV core/GOR47-1 aminoacid homologies $(13-15)$, where the coding sequence for GOR37-1 is part of human DNA (16), already demonstrate such a situation. Although speculative, our findings would theoretically point to at least some 'HCV DNA sequences' being part of a system like human endogenous DNA sequences. This would be similar to a situation comparable with that of the cellular homologue for hepatitis delta antigen (17) or the endogenous retroviral related sequences, HERV (18). The virus-like particles occasionally found in 'HCV infected' cells (19) would not contradict the findings presented here: e. g., virus-like particles originated from endogenous retroviral related sequences can also be found (20). In consequences, this hypothesis could be helpful in developing models for a possible causative role of ' $\mathrm{HCV}$ ' in, e.g., its association with autoimmune phenomenons or disorders $(21-23)$ and hepatocellular carcinomas (3). Further steps must be taken, such as one to characterize sequences flanking those found in the present study, and to identify the location of the HCV specific sequences found: chromosomal or any kind of episomal structure.

\section{Acknowledgements}

We like to thank Prof. Dr. W. G. Wood PhD (Leeds) for his critical reading of the manuscript. 


\section{References}

1. Dennin RH, Chen Z, Zhao Q, Meißner CH. Indications for hepatitis $\mathrm{C}$ virus specific DNA sequences in liver samples from anti-HCV positive patients with different hepatic diseases. Med Microbiol Lett 1994; 3:80-9.

2. Sullivan DE, Gerber MA. Conservation of hepatitis $C$ virus $5^{\prime}$ untranslated sequences in hepatocellular carcinoma and the surrounding liver. Hepatology 1994; 19:551-3.

3. Shimotohno $\mathrm{K}$. Hepatitis $\mathrm{C}$ virus as a causative agent of hepatocellular carcinoma. Intervirology 1995; 38:162-9.

4. Choo Q-L, Kuo G, Weiner AJ, Overby LR, Bradley DW, Houghton M. Isolation of a cDNA clone derived from a bloodborne Non-A, Non-B viral hepatitis genome. Science 1989; 244:359-62.

5. Choo Q-L, Richman K, Han JH, Berger K, Lee C, Dong C, et al. Genetic organization and diversity of the hepatitis $C$ virus. Proc Natl Acad Sci USA 1991; 88:2451-5.

6. Meyers G, Tautz N, Dubovi EJ, Thiel H-J. Viral cytopathogenicity with integration of ubiquitin-coding sequences. Virology 1991; 180:602-16.

7. Chen Z, Zhao Q, Dennin RH. Detection of HCV DNA (sub)genomic equivalents in serum and liver specimens of anti$\mathrm{HCV}$ positive patients [abstract P58-15]. IXth International Congress of Virology; 1993 Aug 8-13; Glasgow, UK.

8. Miyakawa $Y$, Mayumi M. Hepatitis G virus - A true hepatitis virus or an accidental tourist? N Engl J Med 1997; 336:795-6.

9. Miller RH, Purcell RH. Hepatitis C virus shares amino acid sequence similarity with pestiviruses and flaviviruses as well as of two plant virus supergroups. Proc Natl Acad Sci USA 1990; 87:2057-61.

10. Koken SEC, Wamel JLB van, Geelen JLMC, Berkhout B. Functional analysis of the ACTGCTGA sequence motif in the human immunodeficiency virus type 1 long terminal repeat promotor. J Biomed Sci 1994; 1:83-92.

11. Tanaka T, Kato N, Cho M-J, Shimotohno K. A novel sequence found at $3^{\prime}$ terminus of hepatitis $C$ virus genome. Biochem Biophys Res Comm 1995; 215:744-9.

12. Kolykhalov AA, Feinstone SM, Rice CM. Identification of a highly conserved sequence element at the 3 'terminus of hepatitis C virus genome. J Virol 1996; 70:3363-71.

13. Mishiro S, Takeda K, Hoshi Y, Yoshikawa A, Gotanda T, Itoh Y. An autoantibody cross-reactive to hepatitis $C$ virus core and host nuclear antigen. Autoimmunity 1991; 10:269-73.

14. Hosein B, Fang X, Wang CY. Anti-HCV, anti-GOR, and autoimmunity. Lancet 1992; 339:871.

15. Zhang ZX, Chen M, Wallhagen $\mathrm{K}$, Trojnar J, Magnius LO, Wahren B, et al. Molecular basis for antibody cross-reactivity between the hepatitis $\mathrm{C}$ virus core protein and the host-derived GOR protein. Clin Exp Immunol 1994; 96:403-9.

16. Mishiro S, Hoshi Y, Takeda K, Yoshikawa A, Gotanda T, Takahashi K, et al. Non-A, Non-B hepatitis specific antibodies directed at host-derived epoitope: implication for an autoimmune process. Lancet 1990; 336:1400-3.

17. Brazas R, Ganem D. A cellular homolog of hepatitis delta antigen: implication for viral replication and evolution. Science 1996; 274:90-4.

18. Wilkinson DA, Mager DL, Leong J-AC. Endogenous human retroviruses. In: Levy J, editor. The Retroviridae, Vol 3. New York: Plenum Press, 1994:465-535.

19. Mizuno M, Yamada G, Tanaka T, Shimotono K, Takatani M, Tsuji T, et al. Virion-like structures in HeLa G cells transfected with the full-length sequence of the hepatitis $\mathrm{C}$ virus genome. Gastroenterology 1995; 109:1933-40.

20. Löwer R, Löwer J, Kurth R. The viruses in all of us: characteristics and biological significance of human endogenous retrovirus sequences [review]. Proc Natl Acad Sci USA 1996; 93:5177-84.

21. Ryder SK, Koskinas J, Rizzi PM, McFarlane IG, Portman BC, Naouny NV, et al. Hepatocellular carcinoma complicating autoimmune hepatitis: role of hepatitis $\mathrm{C}$ virus. Hepatology $1995 ; 22: 718-22$.

22. Zucker K, Roth D, Cirocco R, Mathew J, Carreno M, Fuller L, et al. Transplant-associated autoimmune mechanisms in human hepatitis C virus infection. J Clin Immunol 1996; 16:60-70.

23. Tran A, Benzaken S, Yang G, Schneider S, Doglio A, Rampal $A$, et al. Chronic hepatitis $C$ and autoimmunity. Good response to immunosuppressive treatment. Dig Dis Sci 1997; 42:77880.

24. Garson JA, Ring CJA, Tuke PW. Improvement of HCV genome detection with 'short' PCR products. Lancet 1991; 338:1466-7.

25. Bukh J, Purcell RH, Miller RH. Importance of primer selection for the detection of hepatitis C virus RNA with the polymerase chain reaction assay. Proc Natl Acad Sci USA 1992; 89:187-91.

Received June 13/October 6, 1997

Corresponding author: Prof. Dr. Reinhard H. Dennin, Institut für Medizinische Mikrobiologie und Hygiene, Medizinische Universität zu Lübeck, Ratzeburger Allee 160, D-23538 Lübeck, Germany 
